\title{
Promoter methylation of death-associated protein kinase and its role in irradiation response in cervical cancer
}

\author{
REBECCA CHING-YU LEUNG ${ }^{1}$, STEPHANIE SI LIU ${ }^{1}$, KELVIN YUEN-KWONG CHAN², \\ KAR-FAI TAM ${ }^{1}$, KAR-LOEN CHAN ${ }^{1}$, LING-CHUI WONG ${ }^{1}$ and HEXTAN YUEN-SHEUNG NGAN ${ }^{1}$ \\ Departments of ${ }^{1}$ Obstetrics and Gynaecology and ${ }^{2}$ Pathology, \\ Queen Mary Hospital, The University of Hong Kong, Hong Kong, P.R. China
}

Received October 23, 2007; Accepted December 14, 2007

\begin{abstract}
This study was aimed at investigating the deathassociated protein kinase (DAPK) promoter methylation and its clinical relevance in cervical cancer. The DAPK promoter methylation was detected by methylation-specific PCR (MSP) and correlated with DAPK mRNA and protein expression. The effect of DAPK expression on the radiosensitivity of the cervical cancer cell line was assessed by overexpressing DAPK in the radioresistant cell line SiHa. DAPK hypermethylation was found in $56.08 \%$ of the cervical cancer samples and was associated with the tumor histological cell type of squamous cell carcinoma ( $\mathrm{p}=0.002)$ and advanced tumor stage $(\mathrm{p}=0.005)$. Subsequently, DAPK protein expression was found to significantly decrease in cervical cancer samples when compared to normal tissues. The DAPK mRNA and protein expression levels were absent or remarkably reduced in $\mathrm{SiHa}$ and HeLa in which the DAPK promoter was hypermethylated. The expression levels of DAPK could be restored after demethylation treatment with 5-aza-2'-deoxycytidine. Overexpressing DAPK in vitro had no significant influence to the survival of the radioresistant $\mathrm{SiHa}$ cell after being challenged by irradiation. Our findings suggest that DAPK might not directly be responsible for the cellular radiosensitivity, however, DAPK hypermethylation appeared to be of prognostic significance in the advanced stages of cervical cancer.
\end{abstract}

\section{Introduction}

Cervical cancer is one of the most common gynecological cancers worldwide. The inactivation of tumor suppressor

Correspondence to: Professor Hextan Yuen-Sheung Ngan, Department of Obstetrics and Gynaecology, 6th floor, Professorial Block, Queen Mary Hospital, Pokfulam Road, Hong Kong, P.R. China E-mail: hysngan@hkucc.hku.hk

Abbreviations: RT-PCR, reverse-transcriptase polymerase chain reaction; DAPK, death-associated protein kinase

Key words: death-associated protein kinase, cervical cancer, methylation genes and activation of oncogenes are important in cervical tumorigenesis. Transcriptional silencing by hypermethylation of the $\mathrm{CpG}$ islands located in the promoter region is a frequent mechanism leading to the inactivation of tumor suppressor genes (1). Aberrant promoter methylation of tumor suppressor genes was found in cervical cancer. The use of the aberrant gene promoter methylation in cervical cancer was shown to be a potential molecular marker (2).

Radiotherapy is an effective treatment for cervical cancer. Failure of therapy is usually due to the resistance of the tumor towards radiotherapy. One cellular mechanism common to various therapeutic regimens, including radiation, is tumor cell death via apoptosis. Our previous study demonstrated a close relationship between spontaneous apoptosis and patients' survival (3). Apoptosis may thus play a role in the response of cervical cancer to radiation treatment.

The death-associated protein kinase (DAPK) gene is a tumor suppressor gene frequently investigated among various cancers. It is a pro-apoptotic gene and participates in various apoptotic systems. The DAPK C-terminal serine-rich tail peptide, which is conserved in death-domain-containing proteins, plays a negative regulatory role in the inhibition of DAPK, whereas the removal of this region enhances the killing activity (4). Hypermethylation of DAPK was frequently reported in various cancers including colon (5), head and neck (6), urinary bladder (7), lung (8-10), B cell lymphoma (11) and ovary (12). In addition, it was associated with the advanced stages of tumor development (13) and a poor prognosis in non-small cell lung carcinoma (14). In sporadic pituitary tumors, the loss of DAPK expression was associated with hypermethylation of the gene promoter.

In the present study, we investigated the prevalence of DAPK promoter hypermethylation in association with the mRNA and protein expression levels in cervical cancer. The prevalence of the promoter methylation was analyzed with the clinical data to reveal their clinical implications. The potential role of DAPK in regulating the cervical cancer cells in response to radiation treatment was also investigated.

\section{Materials and methods}

Sample collection. One hundred and seven cervical cancer samples, 27 of them with paired adjacent non-tumor tissues (including endometrium, ovary and uterus) from the years 1990 
Table I. Primers used in methylation-specific PCR and RNA expression assay.

\begin{tabular}{|c|c|c|c|c|}
\hline & Primers & Sequences $\left(5^{\prime} \rightarrow 3^{\prime}\right)$ & $\operatorname{Tm}\left({ }^{\circ} \mathrm{C}\right)$ & Product size (bp) \\
\hline \multirow[t]{4}{*}{ MSP } & DAPK-MF (M) & GGATAGTCGGATCGAGTTAACGTC & 64 & 98 \\
\hline & DAPK-MR (M) & AGCCGCAAACCCTCCC & & \\
\hline & DAPK-UF (U) & GGAGGATAGTTGGATTGAGTTAATGTT & 60 & 106 \\
\hline & DAPK-UR (U) & AАССАСАААСССТСССТАААС & & \\
\hline \multirow[t]{4}{*}{ RNA expression } & DAPK-F (RNA) & AATCCTAGACGTGGTCCGGTAT & 58 & 155 \\
\hline & DAPK-R (RNA) & GCTTTCCTATGCGTGGCTCCTG & & \\
\hline & B-actin-F (RNA) & АСТCTTCCAGCCTTCСТTCC & 60 & 331 \\
\hline & B-actin-R (RNA) & GTCGTTCGTCCTCATACTGC & & \\
\hline
\end{tabular}

M, methylation-specific primers; $\mathrm{U}$, unmethylation-specific primers.

to 2000 , were retrieved from the frozen tissue bank at the Department of Obstetrics and Gynaecology, Queen Mary Hospital, the University of Hong Kong. Tissue specimens were frozen at $-70^{\circ} \mathrm{C}$ or liquid nitrogen after surgical removal. Ethic approval was obtained from a local institute for the use of these specimens in this study. The mean age of the cancer patients was $52.46 \pm 14.24$ (range: $23-85$ ). Of these 107 patients, 87 were diagnosed with squamous cell carcinoma (SCC); 18 were adenocarcinoma (AD) and 2 were adenosquamous which were grouped into adenocarcinoma for analysis. According to the International Federation of Gynaecology and Obstetrics (FIGO) staging classification, 64 patients were at the early stages (I + IIa) and 43 patients were at the advanced stages (IIb or above) of the disease. Other clinical data, such as HPV status and patients' survival, were also retrieved for data analysis. Blood from 45 noncancer individuals was obtained and used as a normal control.

Among 107 cervical cancer patients, 81 of them received radiotherapy and were divided into radiosensitive (46) and radioresistant (22) groups based on the histological findings of residual tumor cells in the cervical biopsy specimens taken after the completion of radiotherapy (15). Thirteen patients were excluded since they were unable to be followed-up.

Promoter hypermethylation analysis. Genomic DNA was extracted with Proteinase $\mathrm{K}$ treatment followed by the conventional phenol/chloroform extraction and ethanol precipitation method. Sodium bisulfite modification of the genomic DNA was performed as described previously (16). Methylation-specific polymerase chain reaction was performed to examine methylation status at the promoter regions of the DAPK gene. The primer sequences for the methylation and unmethylation-specific allele and PCR conditions are shown in Table I. The amplified products were resolved by $3 \%$ NuSieve agarose gel electrophoresis (Bio Whittaken, Molecular Applications, ME), stained with ethidium bromide and then visualized under a UV light. Sodium bisulfite modified placental DNA was treated with SssI methyltransferase (New England Biolabs, Beverly, MA) for a methylation-positive control to be included in each set of MSP. Positive methylation and unmethylation products were randomly selected for confirmation using direct sequencing.
Cell culture and demethylation treatment. Cervical cancer cell lines, SiHa, HeLa, C4-1, Caski and C-33A were seeded at a density of $3 \times 10^{6}$ cells per plate in Eagle's minimum essential medium supplemented with $10 \%$ fetal bovine serum, $1 \%$ penicillin and streptomycin. The demethylation treatment was performed with five different concentrations $(0,0.5,1,3$ and $5 \mu \mathrm{M}$ ) of 5'-aza-2'-deoxycytidine (5AZA) (Sigma, St. Louis, MO). The cell lines were harvested for RNA, DNA and protein extractions after $72 \mathrm{~h}$ of the treatment.

RNA isolation and reverse transcription polymerase chain reaction $(R T-P C R)$. Total RNA was extracted from the cervical cancer samples and cell lines using TRIzol reagent (Invitrogen, Carlsbad, CA) as recommended by the manufacturer. The quality and quantity of the extracted RNA was checked by gel electrophoresis and spectrophotometer. Total RNA ( $1 \mu \mathrm{g})$ was reverse-transcribed using an oligo$\mathrm{dT}_{12-18}$ and SuperScript II reverse transcriptase (Invitrogen) according to the manufacturer's instructions. The synthesized cDNA were subsequently used to measure the mRNA expression of DAPK by RT-PCR. The expression of $\beta$-actin was used as an internal control for normalization. The primer sequences used for amplification of DAPK and $B$-actin are shown in Table I. The RT-PCR product was resolved by gel electrophoresis. DAPK mRNA expression was semiquantitated by a densitometer with LabWorks ${ }^{\mathrm{TM}}$ Analysis System version 3.0 (UVP, Inc., Upland CA, USA). Cervical cancer samples with DAPK mRNA expression levels lower or higher than $50 \%$ of the normal samples were taken as decreased or increased expression after normalization with the ß-actin.

Immunoblotting analysis. Sixty-two cervical cancer samples were taken for immunoblot analysis. Proteins $(50 \mu \mathrm{g})$ were separated on SDS-PAGE and subsequently transferred onto nitrocellulose paper (Bio-Rad Laboratories, Hercules, CA). Monoclonal anti-DAPK antibody (clone DAPK-55) (Sigma) was diluted in 1:250. In each experiment, monoclonal anti- $\beta$ actin antibody (Sigma) was used to normalize the amount of protein of each sample. A presence of a target band was detected using an ECL chemiluminescent detection kit (Amersham Bioscience, Piscataway, NJ) and autoradiography. 


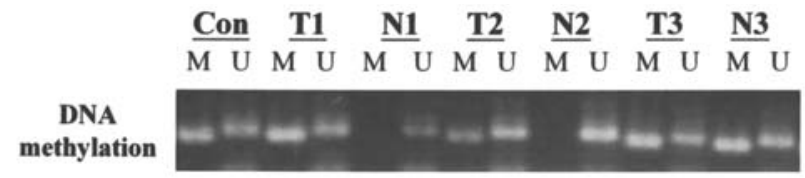

$\begin{array}{llllllll}\text { T4 } & \text { N4 } & \text { T5 } & \text { N5 } & \text { T6 } & \text { N6 } & \text { T7 } & \text { N7 }\end{array}$

\section{DAPK mRNA}

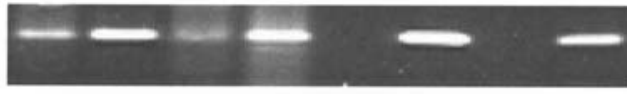

$\beta$-actin mRNA

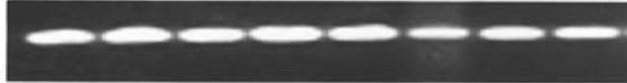

DAPK protein

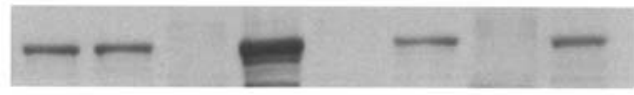

$\beta$-actin protein

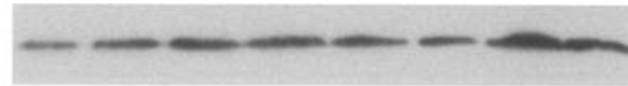

Figure 1. Methylation, mRNA and protein expression analyses of the DAPK gene in representative paired cervical samples are shown. T, tumor sample; $\mathrm{N}$, matched normal sample; and Con, positive control (placental DNA treated with SssI methyltransferase); M, methylated fragment; U, unmethylated fragment.

Table II. Prevalence of DAPK hypermethylation in cervical cancer samples, matched normal tissues and normal blood samples.

\begin{tabular}{lcc}
\hline & $\begin{array}{c}\text { DAPK } \\
\text { hypermethylation }\end{array}$ & p-value \\
\hline Cervical cancer samples & $54.64 \%(60 / 107)$ & \\
Normal tissues & $0 \%(0 / 27)$ & $<0.001^{\text {a }}$ \\
Normal blood & $4.4 \%(2 / 45)$ & $<0.001^{\text {a }}$ \\
\hline
\end{tabular}

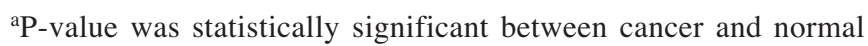
controls obtained by $\chi^{2}$ test.

DAPK protein expression was semi-quantitated with LabWorks Analysis System version 3.0 as described above.

Transfection and clonogenic survival assay. To examine the effect of the expression of DAPK on the radiation response of cervical cancer cells, the radioresistant cell line SiHa was transfected with $1 \mu \mathrm{g}$ of wild-type DAPK expression plasmid (pcDNA3-DAPK) (a gift from Professor A. Kimchi) using FuGENE6 transfection reagents (Roche Applied Science) according to the manufacturer's protocol. Cells without transfection or transfected with the pcDNA3 vector served as controls.

The intrinsic radiosensitivity of the cervical cancer cell line was determined by a clonogenic survival assay as described previously (17). The colony forming ability was calculated by comparing the number of colonies between the irradiated and non-irradiated cells. Colony formation efficiency of the nonirradiated control cells was normalized to $100 \%$ and the (a)

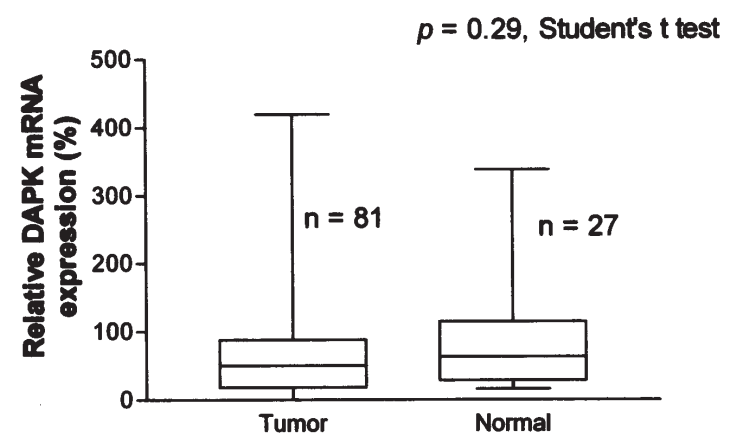

(b)

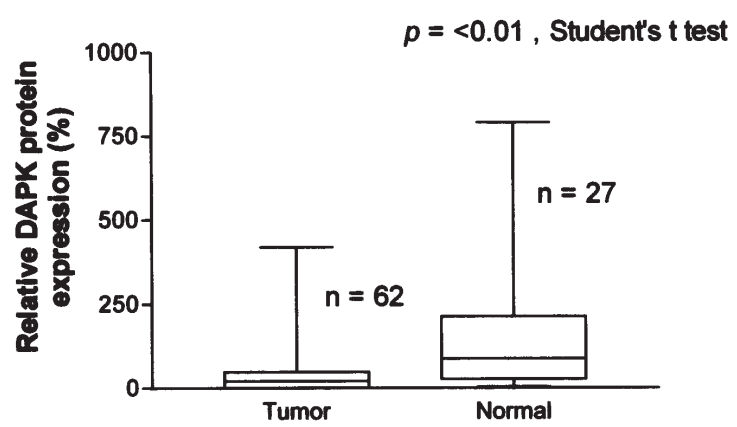

Figure 2. Relative expression levels of DAPK mRNA (a) and protein (b) between cervical cancer samples and normal tissues were measured. DAPK protein expression in normal was found to be significantly higher than the cervical cancer samples $\left(\mathrm{p}<0.001, \chi^{2}\right.$ test).

colony formation efficiency of the irradiated cells was expressed as a percentage of the control survival. The pcDNA3-DAPK transfected SiHa cells were irradiated at 2 Gy with a Gammacell 1000 (Nordion International Inc., Kanata, ON, Canada). After irradiation, the cells were cultured for 10 to 14 days. The cells were subsequently fixed in $70 \%$ ethanol and stained with $1 \%$ Giemsa solution (in water). Colonies consisting of $>50$ cells were scored. Experiments were peformed in triplicate. The surviving fraction at 2 Gy (SF2) was used as an indicator of radiosensitivity (18).

Statistical analysis. Statistical analysis was performed using SPSS version 13.0 (SPSS Inc., Chicago, IL). A comparison was made by the Student's t-test, Fisher's Exact test and $\chi^{2}$ test as appropriate. The Kaplan-Meier method with the logrank test and Cox regression model were used for survival and multivariate analyses, respectively. A p-value $<0.05$ was taken as statistically significant.

\section{Results}

Frequency of DAPK promoter hypermethylation in cervical cancer samples. DAPK promoter hypermethylation was found significantly higher in the cervical cancer samples (60 out of $107,56.08 \%)$ compared to the normal controls ( $0 \%$ in matched normal tissues and $4.4 \%$ in normal blood) (Table II). The methylation patterns of DAPK of representative cases are shown in Fig. 1A. 
Table III. Correlations between clinical parameters and DAPK methylation, mRNA and protein expression levels in cervical cancer samples.

$\begin{array}{ccccc}\begin{array}{c}\text { DAPK } \\ \text { methylation }\end{array} & \text { p-value } & \begin{array}{c}\text { DAPK mRNA } \\ \text { expression }\end{array} & \text { p-value } & \begin{array}{c}\text { DAPK } \\ \text { protein } \\ \text { expression }\end{array}\end{array}$

\section{Age (yrs) \\ $\leq 50$}

$>50$

$28 / 54$

$32 / 53$

$55 / 87$

$5 / 20$

$29 / 64$

$31 / 43$

$35 / 107$

$15 / 107$

0.29

0.37

0.24

$32 / 44$

$25 / 37$

$45 / 64$

$12 / 15$

$0.002^{\mathrm{a}}$

$30 / 46$

$11 / 22$

Radiosensitive

Radioresistant

\section{$\underline{\text { Caski }} \underline{\text { C4-1 }} \underline{\text { C33A SiHa Hela }}$} $M \quad U \quad M \quad U \quad M \quad U \quad M \quad U \quad M \quad U$

DNA methylation

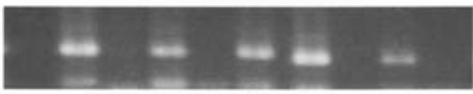

\section{Caski $\underline{\text { C4-1 }} \underline{\text { HeLa }} \underline{\text { C-33A }} \underline{\mathrm{SiHa}}$}

\section{DAPK mRNA}

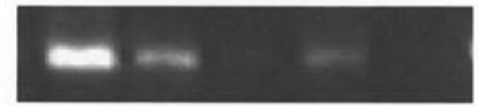

$\beta$-actin mRNA

DAPK protein
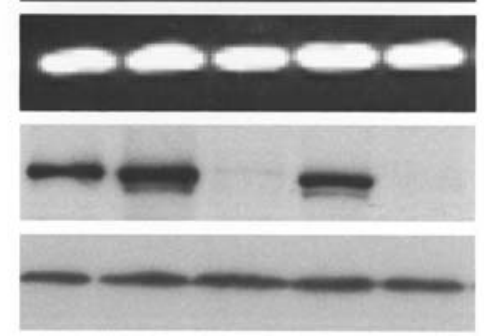

$\beta$-actin protein

Figure 3. Promoter methylation status, mRNA and protein expression levels of DAPK in five cervical cell lines of Caski, C4-1, HeLa, SiHa and C-33A were examined.

DAPK $m R N A$ and protein expression levels in cervical cancer samples. Among 107 cervical cancer samples, 81 samples were available for mRNA expression analysis and 57 of them showed DAPK mRNA expression levels (71.25\%). Increased
DAPK mRNA expression was detected in eight cancer samples, whereas decreased or absence of expression was found in 33 samples. Thirty-nine cancers showed a similar expression level as normal controls. Sixty-two out of 81 cervical cancer samples (assessed for mRNA expression) were also assessed for the DAPK protein expression levels and 44 of them showed positive DAPK protein expression (71\%) (Fig. 1B). DAPK mRNA expression was correlated with the protein expression $(40 / 62, \mathrm{p}=0.03$, Fisher's Exact test) in cervical cancer samples. mRNA and protein expression levels of DAPK were found in every matched normal control tissue. No significant difference in DAPK mRNA expression level was found between the cancer samples and the matched normal tissues $(62.38 \pm 7.51 \%$ and $78.37 \pm 13.14 \%$, respectively, $\mathrm{p}=0.29$ Student's t-test, Fig. 2A). However, a significant decrease of the DAPK protein expression level in the cancer samples (three samples showed an increase, one showed no change and the rest showed either a decrease or absence of expression) was observed when compared to the normal samples $(40.83 \pm 9.1 \%$ and $158.2 \pm 39.39 \%$, respectively, $\mathrm{p}<0.01$, Student's t-test, Fig. 2B). Furthermore, no significant correlation was obtained between DAPK methylation and either mRNA expression $\left(27 / 81, p=0.16, \chi^{2}\right.$ test $)$ or protein expression $(27 / 62, p=0.52$, Fisher's Exact test) in cervical cancer samples.

Methylation and demethylation studies in cell lines. The DAPK promoter was found completely methylated in $\mathrm{SiHa}$ and HeLa, though unmethylated in the Caski, C4-1 and C-33A 


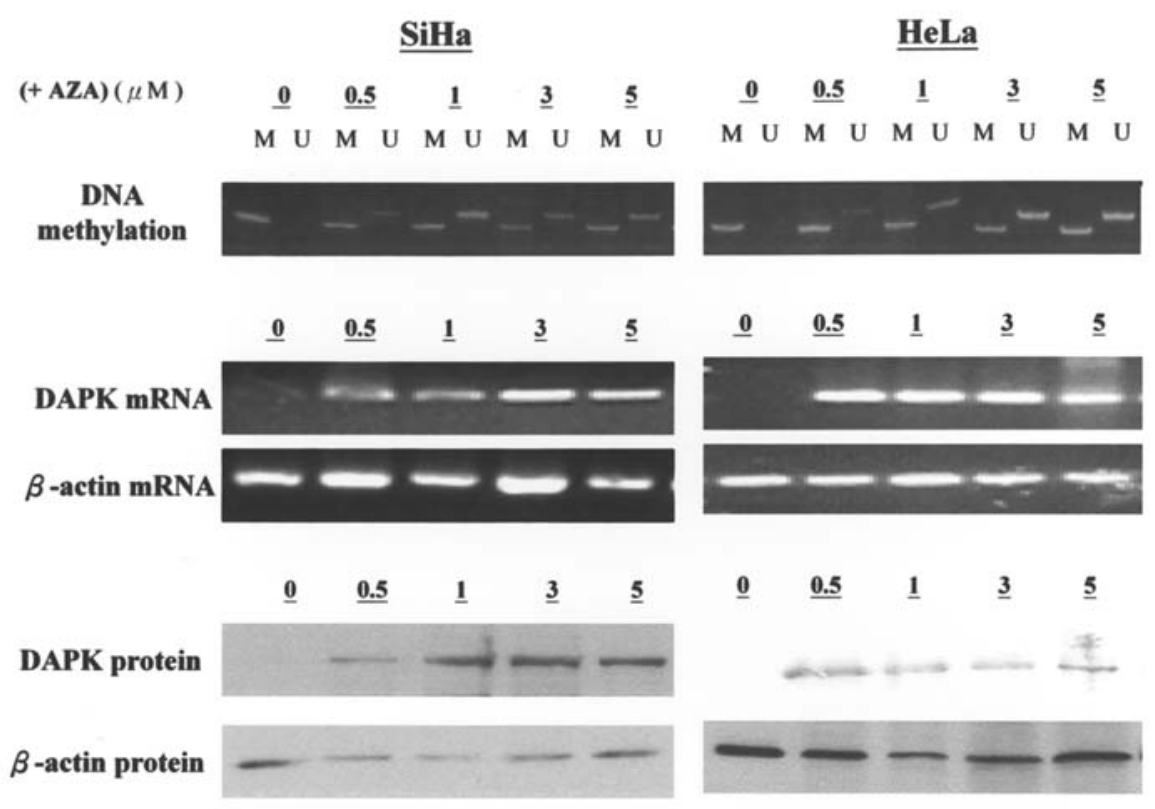

Figure 4. Re-expressions of DAPK mRNA and protein in cervical cancer cell lines SiHa and HeLa after demethylation treatment with 5-aza-2'deoxycytidine (AZA). Four concentrations of AZA from $0.5-5 \mu \mathrm{M}$ were used in cell culture for three days. It was found that the expression levels of DAPK mRNA and protein were restored after demethylation drug treatment in the two cell lines.

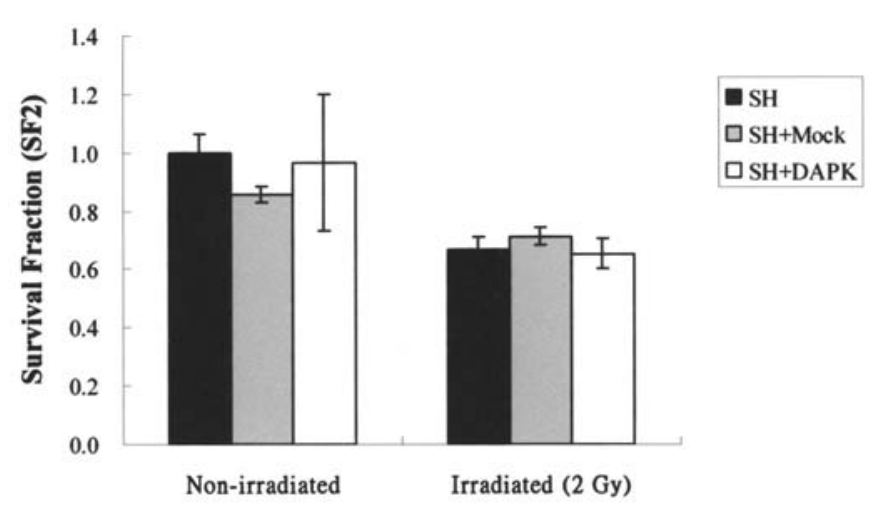

Figure 5. The radiosensitivity of SiHa cells indicated by SF2 was determined after irradiation treatment. SiHa cells were either transfected with the wild-type DAPK (wDAPK) (white bar) or with the vector control (mock) (grey bar). The untransfected cells (black bar) were used as the control and normalization. Average measured values with standard errors were obtained from three independent experiments.

cells (Fig. 3A). The mRNA and protein expression levels of DAPK were present in Caski, C4-1 and C-33A cell lines, though lost in HeLa and $\mathrm{SiHa}$ (Fig. 3B). In order to investigate whether DAPK expression is methylation-dependent, demethylation studies were carried out on SiHa and HeLa cell lines. DAPK mRNA and protein expression levels were restored on the two cell lines after 3 days of demethylation treatment with 0.5-5 $\mu \mathrm{M}$ of AZA (Fig. 4). However, the promoter methylation could not be completely abolished in the cell lines even when using higher dosages $(5 \mu \mathrm{M})$ of AZA (Fig. 4).

Clinicopathological correlations. Prevalence of DAPK promoter hypermethylation, mRNA and protein expression levels in cervical cancers were analyzed with the clinicopathological data and are summarized in Table III. The incidence of DAPK promoter hypermethylation was significantly higher in the SCC type of the cancer and in tumors in the advanced stages $(p=0.002$ and $p=0.005$, respectively, $\chi^{2}$ test). A significant association was not found between the patient's survival and the DAPK promoter hypermethylation; mRNA expression and protein expression ( $\mathrm{p}=0.056 ; \mathrm{p}=0.15$ and $\mathrm{p}=0.46$, respectively, log-rank test $)$.

HPV 16 infection was found more frequently in SCC $(57 / 87,59.87 \%)$ than in AD tumors $(2 / 20,10 \%)(\mathrm{p}<0.001$, $\chi^{2}$ test, data not shown) and in the early stages of cervical cancer (40/64, $\mathrm{p}=0.048, \chi^{2}$ test). While HPV18 infection was found to have a similar infection rate in SCC (22/87, 25.3\%) and $\operatorname{AD}(7 / 20,35 \%)\left(\mathrm{p}=0.27, \chi^{2}\right.$ test, data not shown). DAPK mRNA expression correlated with HPV16 infection in cervical cancer samples $\left(\mathrm{p}=0.042, \chi^{2}\right.$ test $)$, though DAPK protein expression and methylation did not (Table III). Patients with DAPK mRNA expression were found to have a higher HPV16 infection rate than patients without mRNA expression. HPV18 infection did not correlate either with DAPK expression or methylation.

DAPK expression and tumor radiosensitivity. DAPK expression and tumor radiosensitivity were assessed in 81 patients who had undergone radiotherapy. Thirty out of 46 $(65.2 \%)$ radiosensitive and 11 out of $22(50 \%)$ radioresistant cervical cancer samples revealed the DNA hypermethylation in the DAPK promoter. The DAPK mRNA expression was detected in 23 out of 32 radiosensitive (71.9\%) and 9 out of 15 radioresistant samples $(60 \%)$, while the DAPK protein expression was found in 22 out of 26 radiosensitive (84.6\%) and 6 out of 7 radioresistant samples $(85.7 \%)$. However, not the DAPK mRNA or the protein expression levels were correlated with tumor radiosensitivity $(\mathrm{p}=0.313$ and $\mathrm{p}=0.72$, Fisher's Exact test, respectively, Table III). Though no significant correlation was noted, as the promoter methylation contributed to the regulation of the gene expression, the 
investigation using an in vitro cell model was pursued in order to examine the role of DAPK in regulating the cellular radiosensitivity in the cancer. The radiosensitivity of cervical cancer cells was measured by survival fraction at 2 Gy (SF2) using a clonogenic assay (17). SiHa was previously found to be a radioresistant cell line. An in vitro transfection study demonstrated a mild decrease of survival cells in pcDNADAPK transfected SiHa cells compared to the mock transfected control cells after irradiation treatment (Fig. 5).

\section{Discussion}

Hypermethylation of $\mathrm{CpG}$ within the promoter region of the tumor suppressor or other cancer related genes is a common feature of human cancer and is often associated with a transcriptional silencing and loss of a relevant protein (19-21). Since promoter methylation regulates the gene transcriptional status, the hypermethylation of genes involved in cell cycle control and apoptosis might have a pathogenetic role in the development of cancer.

In this study, promoter hypermethylation of DAPK was investigated and was found to be significantly higher in cervical cancer than normal control samples and advanced disease stages. Similar findings were also reported by other studies $(22,23)$. Hypermethylation of DAPK was found to be associated with the SCC type of the cancer. This phenomenon might imply that squamous cell is more susceptible to an epigenetic alteration.

The loss of DAPK expression due to promoter hypermethylation was demonstrated in other cancers $(11,24)$. Since DAPK is a positive mediator of apoptosis, the silencing of DAPK disabled the DAPK-mediated apoptosis and might then prompt metastasis in the cancer cells (25). In addition, cells lacking DAPK expression via promoter methylation became more invasive and metastatic (26). In the cell line model, the DAPK mRNA and protein expression levels were restored after the demethylation drug treatment. Our studies have shown that the DAPK protein expression levels were decreased in cervical cancer samples when compared with the normal tissues. However, DAPK hypermethylation was not correlated with the DAPK protein expression, which might suggest that perhaps the down-regulation of DAPK protein expression in cervical cancer is not dependent on the regulation of the promoter methylation.

DAPK was shown to be a pro-apoptotic gene and in regulation of the apoptotic pathway (27). In our in vitro cell model, the exogenous overexpression of DAPK had no effect on the cellular radiosensitivity. A similar study reported by Tanaka et al revealed no significant relationships between cellular radiosensitivity and DAPK protein expression, or DAPK promoter hypermethylation (28). Our results suggest that DAPK may not have a direct effect on radiation-induced apoptosis. In addition, SiHa is an HPV16-positive cell line in which functional p53 was degraded by the E6 oncoprotien of HPV16. As DAPK-mediated apoptosis required the presence of functional p53, DAPK might not be able to induce apoptosis in the p53-degraded $\mathrm{SiHa}$ after an irradiation challenge. Further investigations on the co-transfection of DAPK and p53 might shed light on the role of DAPK in the regulation of the cellular radiosensitivity.
In summary, our study indicated that DAPK hypermethylation frequently occurred in cervical cancer, especially in squamous cell carcinoma of the cervix. Correlations between DAPK hypermethylation and staging suggested that DAPK hypermethylation had a prognostic significance. No association between DAPK protein expression and cellular radiosensitivity suggested that radiation-induced apoptosis might not be regulated by DAPK, however, this needs to be further investigated.

\section{Acknowledgements}

The pcDNA3-DAPK plasmid was kindly provided by Professor A. Kimchi. This study was partially supported by research grant CRGC 2002/2003-1020439 of the University of Hong Kong, Hong Kong.

\section{References}

1. Baylin SB, Herman JG, Graff JR, Vertino PM and Issa JP: Alterations in DNA methylation: a fundamental aspect of neoplasia. Adv Cancer Res 72: 141-196, 1998.

2. Esteller M: Relevance of DNA methylation in the management of cancer. Lancet Oncol 4: 351-358, 2003.

3. Liu SS, Tsang BK, Cheung AN, Xue WC, Cheng DK, Ng TY, Wong LC and Ngan HY: Anti-apoptotic proteins, apoptotic and proliferative parameters and their prognostic significance in cervical carcinoma. Eur J Cancer 37: 1104-1110, 2001.

4. Raveh T, Berissi H, Eisenstein M, Spivak T and Kimchi A: A functional genetic screen identifies regions at the $\mathrm{C}$-terminal tail and death-domain of death-associated protein kinase that are critical for its proapoptotic activity. Proc Natl Acad Sci USA 97: $1572-1577,2000$

5. Kissil JL and Kimchi A: Death-associated proteins: from gene identification to the analysis of their apoptotic and tumour suppressive functions. Mol Med Today 4: 268-274, 1998.

6. Sanchez-Cespedes M, Esteller M, Wu L, Nawroz-Danish H, Yoo GH, Koch WM, Jen J, Herman JG and Sidransky D: Gene promoter hypermethylation in tumors and serum of head and neck cancer patients. Cancer Res 60: 892-895, 2000.

7. Chan MW, Chan LW, Tang NL, Tong JH, Lo KW, Lee TL, Cheung HY, Wong WS, Chan PS, Lai FM, et al: Hypermethylation of multiple genes in tumor tissues and voided urine in urinary bladder cancer patients. Clin Cancer Res 8: 464-470, 2002.

8. Esteller M, Sanchez-Cespedes M, Rosell R, Sidransky D, Baylin SB and Herman JG: Detection of aberrant promoter hypermethylation of tumor suppressor genes in serum DNA from non-small cell lung cancer patients. Cancer Res 59: 67-70, 1999.

9. Kim DH, Nelson HH, Wiencke JK, Zheng S, Christiani DC, Wain JC, Mark EJ and Kelsey KT: p16(INK4a) and histologyspecific methylation of $\mathrm{CpG}$ islands by exposure to tobacco smoke in non-small cell lung cancer. Cancer Res 61: 3419-3424, 2001.

10. Wong TS, Chang HW, Tang KC, Wei WI, Kwong DL, Sham JS, Yuen AP and Kwong YL: High frequency of promoter hypermethylation of the death-associated protein-kinase gene in nasopharyngeal carcinoma and its detection in the peripheral blood of patients. Clin Cancer Res 8: 433-437, 2002.

11. Katzenellenbogen RA, Baylin SB and Herman JG: Hypermethylation of the DAP-kinase CpG island is a common alteration in B-cell malignancies. Blood 93: 4347-4353, 1999.

12. Collins Y, Dicioccio R, Keitz B, Lele S and Odunsi K: Methylation of death-associated protein kinase in ovarian carcinomas. Int J Gynecol Cancer 16: 195-199, 2006.

13. Kim DH, Nelson HH, Wiencke JK, Christiani DC, Wain JC, Mark EJ and Kelsey KT: Promoter methylation of DAP-kinase: association with advanced stage in non-small cell lung cancer. Oncogene 20: 1765-1770, 2001.

14. Tang X, Khuri FR, Lee JJ, Kemp BL, Liu D, Hong WK and Mao L: Hypermethylation of the death-associated protein (DAP) kinase promoter and aggressiveness in stage I non-small-cell lung cancer. J Natl Cancer Inst 92: 1511-1516, 2000. 
15. Liu SS, Leung RC, Chan KY, Chiu PM, Cheung AN, Tam KF, $\mathrm{Ng}$ TY, Wong LC and Ngan HY: p73 expression is associated with the cellular radiosensitivity in cervical cancer after radiotherapy. Clin Cancer Res 10: 3309-3316, 2004.

16. Chan KY, Ozcelik H, Cheung AN, Ngan HY and Khoo US: Epigenetic factors controlling the BRCA1 and BRCA2 genes in sporadic ovarian cancer. Cancer Res 62: 4151-4156, 2002.

17. Liu SS, Chan KY, Leung RC, Law HK, Leung TW and Ngan HY: Enhancement of the radiosensitivity of cervical cancer cells by overexpressing p73alpha. Mol Cancer Ther 5: 1209-1215, 2006.

18. Tam KF, Ng TY, Liu SS, Tsang PC, Kwong PW and Ngan HY: Potential application of the ATP cell viability assay in the measurement of intrinsic radiosensitivity in cervical cancer. Gynecol Oncol 96: 765-770, 2005.

19. Esteller M, Corn PG, Baylin SB and Herman JG: A gene hypermethylation profile of human cancer. Cancer Res 61 : 3225-3229, 2001.

20. Herman JG, Merlo A, Mao L, Lapidus RG, Issa JP, Davidson NE, Sidransky D and Baylin SB: Inactivation of the CDKN2/p16/ MTS1 gene is frequently associated with aberrant DNA methylation in all common human cancers. Cancer Res 55: 4525-4530, 1995

21. Merlo A, Herman JG, Mao L, Lee DJ, Gabrielson E, Burger PC, Baylin SB and Sidransky D: 5' CpG island methylation is associated with transcriptional silencing of the tumour suppressor p16/CDKN2/MTS1 in human cancers. Nat Med 1: 686-692, 1995.
22. Dong SM, Kim HS, Rha SH and Sidransky D: Promoter hypermethylation of multiple genes in carcinoma of the uterine cervix. Clin Cancer Res 7: 1982-1986, 2001.

23. Narayan G, Arias-Pulido H, Koul S, Vargas H, Zhang FF, Villella J, Schneider A, Terry MB, Mansukhani M and Murty VV: Frequent promoter methylation of CDH1, DAPK, RARB and HIC1 genes in carcinoma of cervix uteri: its relationship to clinical outcome. Mol Cancer 2: 24, 2003.

24. Kissil JL, Feinstein E, Cohen O, Jones PA, Tsai YC, Knowles MA, Eydmann ME and Kimchi A: DAP-kinase loss of expression in various carcinoma and B-cell lymphoma cell lines: possible implications for role as tumor suppressor gene. Oncogene 15: 403-407, 1997.

25. Inbal B, Cohen O, Polak-Charcon S, Kopolovic J, Vadai E, Eisenbach L and Kimchi A: DAP kinase links the control of apoptosis to metastasis. Nature 390: 180-184, 1997.

26. Soria JC, Rodriguez M, Liu DD, Lee JJ, Hong WK and Mao L: Aberrant promoter methylation of multiple genes in bronchial brush samples from former cigarette smokers. Cancer Res 62 351-355, 2002.

27. Raveh T, Droguett G, Horwitz MS, DePinho RA and Kimchi A: DAP kinase activates a p19ARF/p53-mediated apoptotic checkpoint to suppress oncogenic transformation. Nat Cell Biol 3: $1-7,2001$.

28. Tanaka T, Bai T, Yukawa K and Umesaki N: Radiation-induced cell death is independent of the apoptotic signals mediated by death-associated protein kinase in human cervical squamous cell carcinoma cells. Oncol Rep 14: 949-955, 2005. 